\title{
Radical cystectomy with W-shaped orthotopic ileal neobladder constructed with non-absorbable titanium staples-long term follow-up
}

\author{
Sergey Kravchick, Leonid Lobik, Adrian Paz, Eugeny Stepnov, David Ben-Dor, Shmuel Cytron \\ Department of Urology (SK, LL, AP, ES, SC) and Department of Pathology (DBD), Barzilai Med. Center, \\ Ashkelon, Israel
}

\section{ABSTRACT}

Purposes: We retrospectively assessed our experience with the $\mathrm{W}$-shaped orthotopic ileal pouch, which was constructed with non -absorbable titanium staples. For these purpose, we discuss the results of bladder capacity, urinary continence and early and long-term postoperative complications.

Materials and Methods: We included in the study 17 patients who underwent radical cystoprostatectomy followed by construction of an orthotopic W-shaped ileal pouch between October 2000 and November 2009. A 65-70 cm segment of ileum was isolated and prearranged into a $\mathrm{W}$ - configuration, leaving two $10 \mathrm{~cm}$ intact segments on both sides of the ileal fragment. In our technique we entirely anatomized all adjacent limbs in order to create a sphere-shaped pouch. The ureters were directly anastomized to both intact segments of the ileal division. All our patients underwent pouchscopy 6 months after operation and annually.

Results: Mean operative time for neobladder reconstruction and ureteral anastomoses was $87 \pm 7.67$ minutes. In one patient a leak from the ileo-ileal anastomosis was confirmed on the 3 rd day after operation. In 2 cases unilateral stricture of the ureteral-neobladder anastomosis was documented. Staple lines were mostly covered with ileal mucosa after 6 months. The mean functional bladder capacity was $340 \pm 27.6 \mathrm{~mL}$ and $375 \pm 43.4 \mathrm{~mL}$ at 6 and 12 months, respectively. First-year daytime and nighttime continence was good and acceptable in 90\% and 78\% of patients, while it increased to 95\% during the 2nd year. Conclusions: The long term follow-up shows that non-absorbable titanium staples can be safely used for creation of an orthotopic ileal neobladder. However, these data should be further validated in a larger series of patients.

\section{ARTICLE INFO}

\section{Key words:}

blabber neoplasm, cystectomy, laparoscopy, urinary diversion

Int Braz J Urol. 2013; 39: 167-72

Submitted for publication: August 21, 2012

Accepted after revision: January 18, 2013

\section{INTRODUCTION}

Since the first report of successful laboratory and clinical data of stapled bladder closure with titanium staples (1), several studies have adopted this technique with encouraging results (2-6). This technique possesses several advantages, such as decreased operative time, excellent tissue adaptation and presumably watertight closure. However, the possibility of urinary stone formation on the staples requires long term follow-up (1). In this study we describe our technique for W-shaped orthotopic ileal pouch construction with non-absorbable titanium staples and report the results of long term follow-up. 


\section{MATERIALS AND METHODS}

Between October 2000 and November 2009 seventeen males with invasive high grade carcinoma of urinary bladder underwent radical cystoprostatectomy with orthotopic W-shaped ileal pouch, which was constructed with non-absorbable staples. Six patients underwent this operation with a laparoscopic approach, in which case the pouch was created after surgical specimen removal through an additional $7 \mathrm{~cm}$ incision. The criteria for inclusion in the study were: non-metastatic disease, negative biopsies from prostatic urethra, adequate renal function (serum creatinine $<1.5 \mathrm{mg} / \mathrm{dL}$ ), normal liver function, no active inflammatory bowel disease or previous extensive bowel resection (for laparoscopic procedure), physical and mental ability to live with a bladder substitute and the ability to perform self catheterization if needed, and compliance with routine follow-up.

\section{Technique}

Open (n-11) radical cystoprostatectomy was performed in the usual manner. In all laparoscopic cases (n-6) we used a 5-port transperitoneal approach (7-9) and a 2-arm spring-loaded

Figure 1A - A 40-45 cm segment of the isolated ileum is prearranged into $W$ configuration, leaving two intact segments on both sides of the ileal fragment. An opening was created on the pointed distal loop.

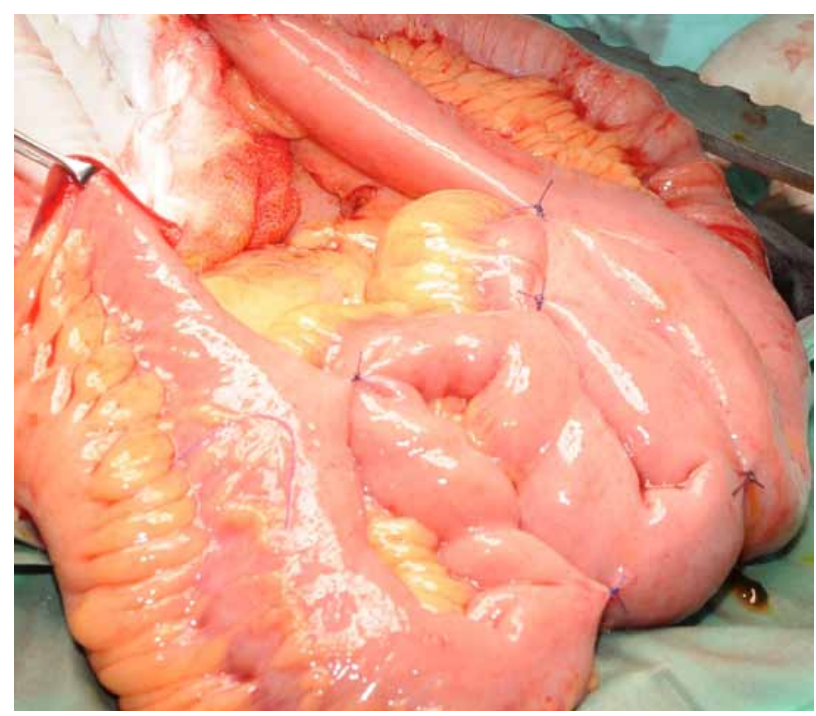

articulating instrument holder (Endoholder). In laparoscopic cases the surgical specimen was removed intact through an additional $7 \mathrm{~cm}$ incision. Afterwards we isolated a $65-70 \mathrm{~cm}$ segment of ileum $20 \mathrm{~cm}$ proximally from the ileocecal valve. The most dependent part of the segment, that could easily reach the top of the symphysis pubis, was pointed and marked with a suture. The ileum was then divided between bowel clamps and a standard bowel anastomosis was performed with staples. The mesenteric trap was closed. A $40-45 \mathrm{~cm}$ segment of the isolated ileum was prearranged into $\mathrm{W}$ configuration, leaving two intact segments on both sides of the ileal fragment in order to decrease the tension on the ureteral anastomoses. In our version of the W-shaped technique all adjacent limbs were entirely anastomosed "side by side". For this purpose, an opening was created on the pointed distal loop of the segment and a 80X3.5 mm mechanical stapler (Multifire GIA - US Surgical) was inserted through the opening and fired (Figures $1 \mathrm{~A}$ and $\mathrm{B}$ ). Later, additional openings were made on the proximal part of the segment and $60 / 80 X 3.5 \mathrm{~mm}$ mechanical staplers were inserted and fired in order to create a sphere-shaped pouch (Figures $1 \mathrm{C}$ and D).

Figure 1B - 80X3.5 mm mechanical stapler (Multifire GIA - US Surgical) is inserted through the distal opening and fired.

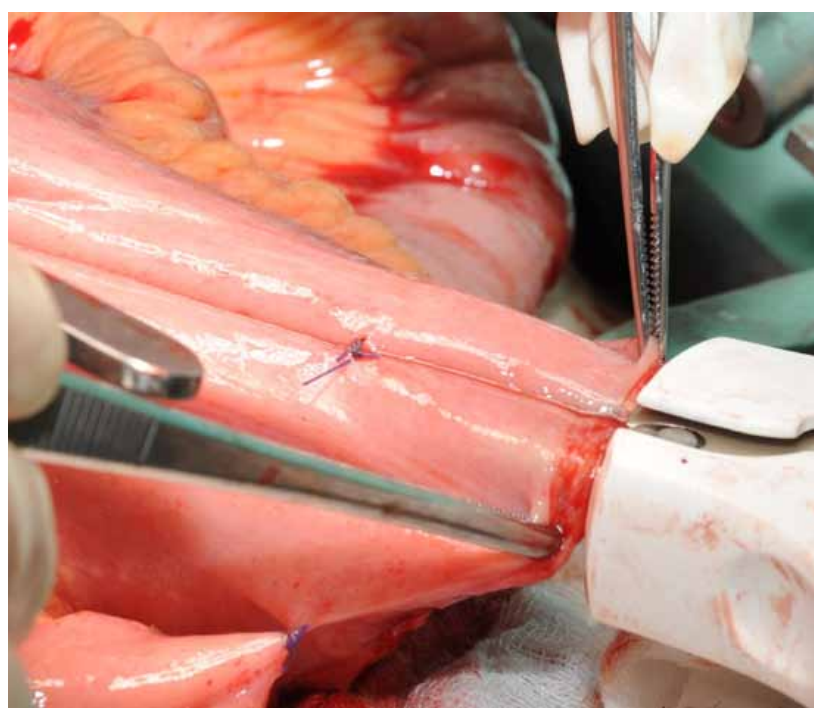


Figure $1 \mathrm{C}$ - The additional opening is made on the proximal part of the segment and $60 / 80 \times 3.5 \mathrm{~mm}$ mechanical staplers is inserted and fired.

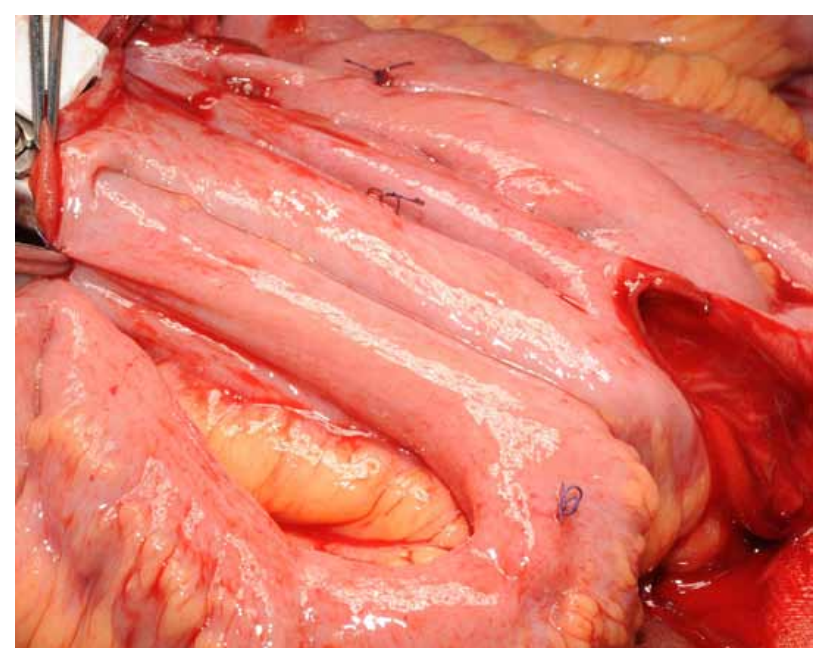

Afterwards, 2 single J stents were inserted up to the renal pelvis and the ureters were directly anastomosed to the intact segments of the ileal division, according to the Wallace technique. The distal ends of the stents were taken out through the separate small openings on the lateral walls of the pouch. Finally, the proximal openings in the pouch, which were made for the staplers insertion, were closed with running absorbable sutures, leaving the distal outlet open. The neobladder was placed inside the abdominal cavity and a $22 \mathrm{Fr}$ silicone Foley catheter was inserted in the urethra. The pouch was anastomosed to the urethra with six interrupted 3-0 monocryl sutures over a 22F Foley. All knots were tied in the outside manner.

\section{Postoperative and follow-up protocols}

The urethral Foley catheter was irrigated with $50 \mathrm{~mL}$ of saline every 4 to 6 hours for the first 2 to 3 postoperative days. Starting from the 4th day it was irrigated with $100 \mathrm{~mL}$ every 8 hours. The Jackson-Pratt drains were removed as drainage decreased to less than $100 \mathrm{~mL}$. If the cystogram on postoperative day 14 excluded any urinary extravasation, the left ureteral stent was removed first, followed 24 hours later by the right stent. The urethral catheter was removed between days 18-21.

During the first months all patients were instructed to void in a sitting position by rela-
Figure 1D - A sphere-shaped pouch is created.

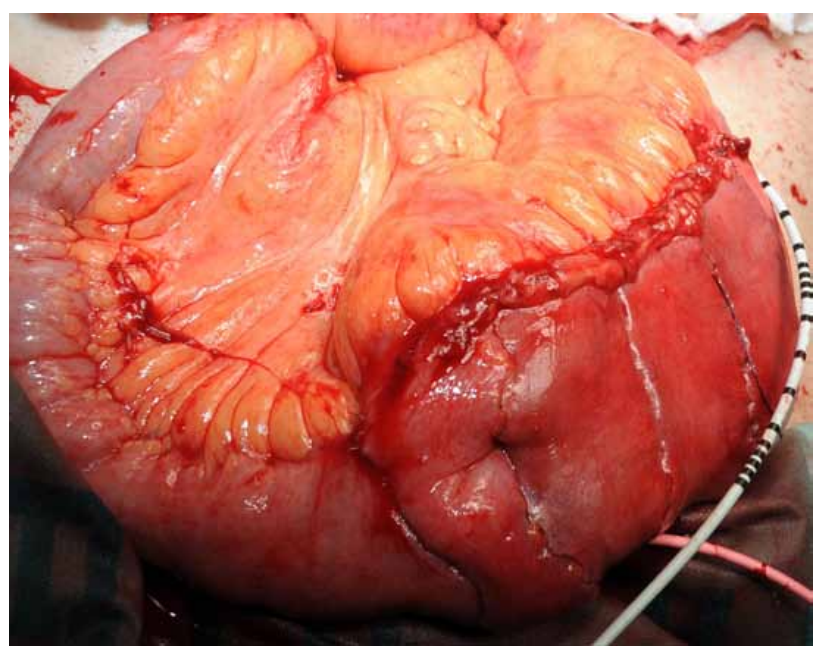

xation of the pelvic floor, followed by slight abdominal straining. Effectiveness of emptying was maintained by hand pressure on the lower abdomen and bending forward. We asked our patients to perform daily self catheterization and pouch irrigation during the first month in order to decrease the chance of mucous blockage. Through the first 2 months patients were instructed to void every 3-4 hours during the day and every 4 hours at night. All our patients underwent pouchscopy 6 months after operation and annually.

We carried out cystometry 6/12 months postoperatively in all patients. Maximal neobladder capacity was identified based on the maximal discomfort in the lower abdomen or urethral leakage. We asked patients to fill out voiding charts to assess functional neobladder capacity and postvoiding residual volume (measured by catheter insertion). We also inquired that the patients grade their day and night time continence as good (no need for pad), acceptable (1-2 pads) or poor ( $>2$ pads). To exclude the detrimental effect (obstruction) of the anti- peristaltic segment of ileum which was used for uretero-ileal anastomosis, all patients underwent renal scan.

\section{RESULTS}

Patients' ages ranged from 47 to 72 years with a mean age of $68 \pm 6.23$. Mean time for 
orthotopic ileal-neobladder reconstruction and ureteral anastomoses was $87 \pm 7.67$ minutes. No tumor was found in 2 postoperative specimens. In the other patients pathology reported T1 low grade (n-2), T1 high grade (n-4), T2 high grade (n-5), T2 high grade with CIS (n-1) and T3 a-b high grade TCC (n-3). Positive lymph nodes were found in 4 specimens. No sign of leakage was found on postoperative cystograms. Three patients suffered from upper tract UTI in the early postoperative period (Clavien Grade 2). In one patient a leak was confirmed from the intestinal anastomosis (ileo-ileal) on the 3rd day after operation (Clavien Grade 3b).

Five patients died from metastatic disease in the first 3 years after operation and two patients died from concomitant diseases (2 and 6 years, respectively). Mean follow-up was $64.76 \pm 23.6$ months. Seven patients remained in follow-up $>5$ years (6-8 years) and six patients $\geq 3$ years ( $3-5$ years), while 4 patients were followed for $\leq 2$ years.

During the first six months after operation daytime continence was good and acceptable in 90\% (no or 1-2 pads), while nighttime continence was good and acceptable in $78 \%$ of patients. However, starting from the second half of the year daytime continence increased to 95\%. One half year after surgery the mean maximal neobladder capacity was $395 \pm 65.3 \mathrm{~mL}$, while one year after operation it was $463 \pm 59.4 \mathrm{~mL}$. The mean functional bladder capacity was $340 \pm 27.6 \mathrm{~mL}$ and $375 \pm 43.4 \mathrm{~mL}$ at 6 and 12 months, respectively. Only three patients still used self catheterization 3 years after operation.
In 2 patients UTI developed 6 to 37 months after operation. Creatinine rose $>0.5 \mathrm{mg} / \mathrm{dL}$ from the "baseline" in 5 patients, while renal scan confirmed deterioration of the renal function in three of them (Clavien Grade 4a): two in the right and one in the left unit. In 8 patients treatment with vitamin B12 was started due to anemia. In two cases mild unilateral stricture of the right ureteral-neobladder anastomosis was suspected on control CT urography. In both cases renal scan (99mTc-MAG3) was followed by furosemide administration with a separate 20-min assessment and was interpreted as an equivocal result.

Cystoscopic control of the pouch revealed that the staple lines were mostly covered with ileal mucosa 6 months after operation (Figures $2 \mathrm{~A}$ and B). Small calculi $0.5-1 \mathrm{~cm}$ were found in 4 patients 2-6 years after operation and in all these cases the calculi passed spontaneously or were removed with a basket during follow-up flexible cystoscopy. We failed to find staple material in the nucleus of the stones.

\section{DISCUSSION}

The experience of general surgeons, who pioneered staplers for anastomosis construction during bowel resection and reconstruction, has shown that this device may decrease operative time, simplify tissue adaptation and guarantee leak proof closure (10-12). Consequently, the results of operation can become less dependent on

Figures 2 - A and B - Staple lines are mostly covered with ileal mucosa.
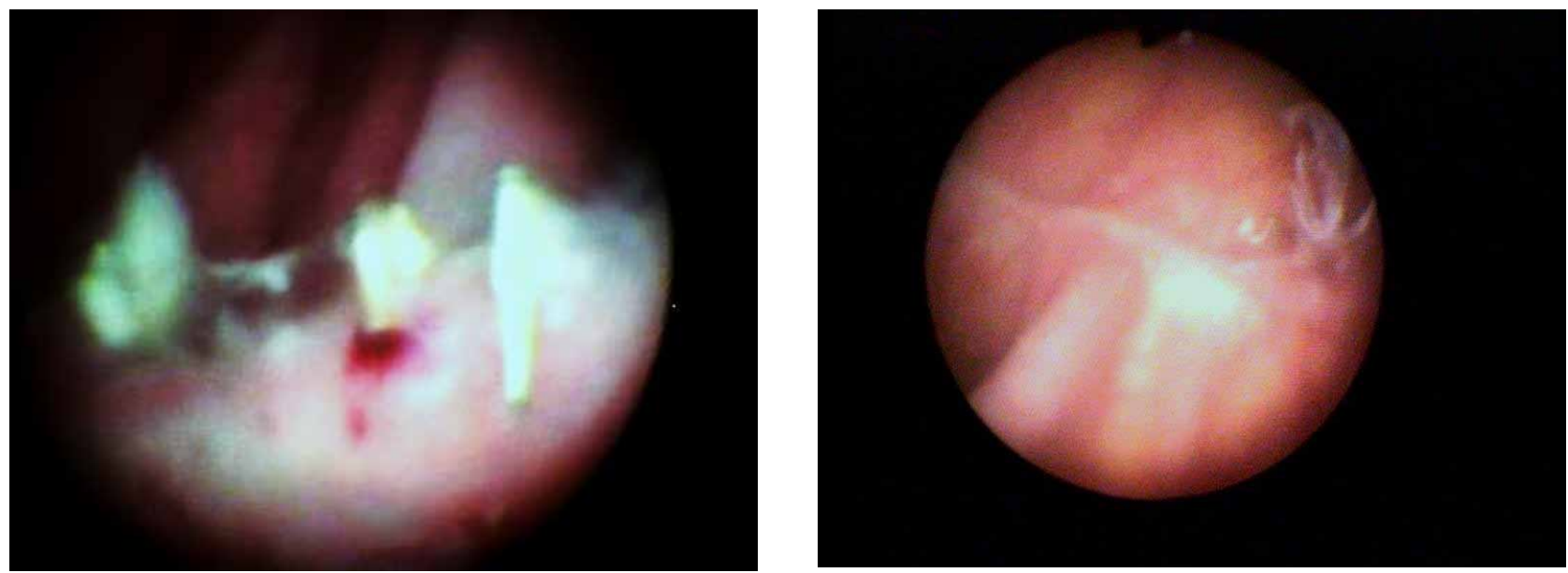
the operators' experience. Since 1993 urologists also began using stapling devices for laparoscopic bladder closure $(1,2)$. Kerbl et al. performed laboratory and clinical studies and reported no intraand postoperative complications, with no episodes of stone formation 3-5 months after operation (1). However, at that time, these authors warned that previous experience with stainless steel staples in ileal loop diversion and Kock pouch had shown stone occurrence in 1.8-10\% and in $16.7 \%$ of the patients, respectively. Later on, Shalhav et al. discussed the results of long-term follow-up (greater than 7 years) after bladder closure with titanium staples and reported no stone formation on the closure line or within the bladder (3). In addition, Grubb et al. reported that Endo-GIA stapler used for renal pelvis closure possessed no risk for stone formation in the short term period (4).

Endoscopic control of neobladder in our study showed that urothelium had covered the staple line six months after operation. These results are in accordance with the data reported by Abreu et al. $(5,6)$. However, small stones were found in $4(26 \%)$ of 17 patients. In all of these cases, the stones passed spontaneously or were removed with a basket. Subsequent analysis failed to find staple material in the nucleus of the calculi. Therefore, we agree that calculi formation in neobladder might be explained by another cause, including metabolic changes and other processes that take place in the pouch $(13,14)$. Although the rates of stone formation in our study were a little bit higher than those previously reported $(5,6,13,15,16)$, we believe that long-term follow-up and relative frequent endoscopic control might explain this discrepancy.

Ureteral stricture is one of the most controversial issues in ileal pouch construction, because it can cause renal damage. In an attempt to decrease their incidence, one should avoid excessive ureteral mobilization, devascularization and anastomotic tension. Based on the previous study of Montie et al., we used chimneys on the both sides of ileal loop in order to advance them towards the end of ureters (17). Anastomotic strictures occurred in two cases and were successfully treated with minimal endoscopic procedures. Although the stricture rate in our study was higher than that reported by Fontana et al., it is still comparable with the results of other studies (18). We also failed to find any sign of obstruction of the uretero-ileal anastomosis on the antiperistaltic site of neobladder.

Our version of the $\mathrm{W}$-neobladder construction provided comparable maximal and functional bladder capacity due to the long detubularized segment and entirely anastomosed limbs. The storage capacity of our reservoir was much better than that reported by Montie et al. (17). As a result, good/acceptable daytime and nighttime continence was reported in $90 \%$ and $78 \%$ of the patients six months after operation. By the end of the first year daytime continence improved and reached 95\%. These results are very similar to those previously reported by other authors, who constructed different types of neobladder $(19,20)$. However, it must be emphasized that other studies had reported superior functional bladder capacity at the end of the first year (21). In these studies absorbable sutures were used, and this fact makes us to suggest that staplers line may restrain bladder functional capacity during the first years.

We presume that our study comes from a relatively "low volume" hospital and this fact can inversely affect the results of long-term follow-up (22). However, the success rates and the percentage of complications are very comparable with the data reported by "high volume hospitals/surgeons". In this context we would like to agree that mechanical staplers simplify the operation and makes its results less dependent on operator experience.

\section{CONCLUSIONS}

Long term follow-up shows that non-absorbable titanium staples can be safely used for the creation of an orthotopic ileal neobladder. Staple lines are typically covered with urothelium 6 months after operation. With strict annual follow-up the rates of small stone formation in this type of neobladder were higher than in the other series. Storage characteristics of ileal reservoir constructed by our version are comparable with other types of orthotopic pouches. This technique is fast, reliable and may help to decrease the difference between the low and high volume centers. 


\section{CONFLICT OF INTEREST}

\author{
None declared.
}

\section{REFERENCES}

1. Kerbl K, Chandhoke P, McDougall E, Figenshau RS, Stone AM, Clayman RV: Laparoscopic stapled bladder closure: laboratory and clinical experience. J Urol. 1993; 149: 1437-9; discussion 1439-40.

2. Chandhoke PS, Clayman RV, Kerbl K, Figenshau RS, McDougall EM, Kavoussi LR, et al.: Laparoscopic ureterectomy: initial clinical experience. J Urol. 1993; 149: 992-7.

3. Shalhav AL, Dunn MD, Portis AJ, Elbahnasy AM, McDougall EM, Clayman RV: Laparoscopic nephroureterectomy for upper tract transitional cell cancer: the Washington University experience. J Urol. 2000; 163: 1100-4.

4. Grubb RL 3rd, Sundaram CP, Yan Y, Chen C, McDougall EM, Clayman RV: Use of titanium staples during upper tract laparoscopic reconstructive surgery: initial experience. J Urol. 2002; 168: 1366-9.

5. Abreu SC, Messias FI, Argollo RS, Guedes GA, Araujo MB, Fonseca GN: Laparoscopic assisted radical cystoprostatectomy with Y-shaped orthotopic ileal neobladder constructed with non-absorbable titanium staples through a $5 \mathrm{~cm}$ Pfannensteil incision. Int Braz J Urol. 2005; 31: 362-7; discussion 368-9.

6. Abreu SC, Araújo MB, Silveira RA, Regadas RP, Pinheiro DG, Messias Fl, et al.: Laparoscopic-assisted radical cystectomy with U-shaped orthotopic ileal neobladder constructed using nonabsorbable titanium staples. Urology. 2006; 68: 193-7.

7. Gill IS, Fergany A, Klein EA, Kaouk JH, Sung GT, Meraney AM, et al.: Laparoscopic radical cystoprostatectomy with ileal conduit performed completely intracorporeally: the initial 2 cases. Urology. 2000; 56: 26-9; discussion 29-30.

8. Moinzadeh A, Gill IS: Laparoscopic radical cystectomy with urinary diversion. Curr Opin Urol. 2004; 14: 83-7.

9. Basillote JB, Abdelshehid C, Ahlering TE, Shanberg AM: Laparoscopic assisted radical cystectomy with ileal neobladder: a comparison with the open approach. J Urol. 2004; 172: 489-93.

10. Kracht M, Hay JM, Fagniez PL, Fingerhut A: Ileocolonic anastomosis after right hemicolectomy for carcinoma: stapled or hand-sewn? A prospective, multicenter, randomized trial. Int J Colorectal Dis. 1993; 8: 29-33.

11. Gustavsson K, Gunnarsson U, Jestin P: Postoperative complications after closure of a diverting ileostoma--differences according to closure technique. Int J Colorectal Dis. 2012; 27: 55-8.
12. Leung TT, MacLean AR, Buie WD, Dixon E: Comparison of stapled versus handsewn loop ileostomy closure: a meta-analysis. J Gastrointest Surg. 2008; 12: 939-44.

13. Terai A, Ueda T, Kakehi Y, Terachi T, Arai Y, Okada Y, et al.: Urinary calculi as a late complication of the Indiana continent urinary diversion: comparison with the Kock pouch procedure. J Urol. 1996; 155: 66-8.

14. Osther PJ, Poulsen AL, Steven K: Stone risk after bladder substitution with the ileal-urethral Kock reservoir. Scand J Urol Nephrol. 2000; 34: 257-61.

15. Fontana D, Bellina M, Fasolis G, Frea B, Scarpa RM, Mari M, et al.: Y-neobladder: an easy, fast, and reliable procedure. Urology. 2004; 63: 699-703.

16. Turk TM, Koleski FC, Albala DM: Incidence of urolithiasis in cystectomy patients after intestinal conduit or continent urinary diversion. World J Urol. 1999; 17: 305-7.

17. Montie JE, Pontes JE, Parulkar BG, Selby T: W-stapled ileal neobladder formed entirely with absorbable staples. J Urol. 1994; 151: 1188-92.

18. Shaaban AA, Abdel-Latif M, Mosbah A, Gad H, Eraky I, Ali-ElDein $B$, et al.: A randomized study comparing an antireflux system with a direct ureteric anastomosis in patients with orthotopic ileal neobladders. BJU Int. 2006; 97: 1057-62.

19. Madersbacher S, Möhrle K, Burkhard F, Studer EU: Long-term voiding pattern of patients with ileal orthotopic bladder substitutes. J Urol. 2002; 167: 2052-7.

20. Rogers E, Scardino PT: A simple ileal substitute bladder after radical cystectomy: experience with a modification of the Studer pouch. J Urol. 1995; 153: 1432-8.

21. Marim G, Bal K, Balci U, Girgin C, Dinçel C: Long-term urodynamic and functional analysis of orthotopic "W" ileal neobladder following radical cystectomy. Int Urol Nephrol. 2008; 40: 629-3.

22. Goossens-Laan CA, Gooiker GA, van Gijn W, Post PN, Bosch $\mathrm{JL}$, Kil PJ, et al.: A systematic review and meta-analysis of the relationship between hospital/surgeon volume and outcome for radical cystectomy: an update for the ongoing debate. Eur Urol. 2011; 59: 775-83. 